\title{
Comfort evaluation of bridge based on stochastic process theory
}

\author{
Y Tan' ${ }^{1}$, S Qin ${ }^{2}$, Z Zhang ${ }^{1}$, H Wang ${ }^{* 1,3}$ and Q Wang ${ }^{4}$ \\ ${ }^{I}$ National \& Local Joint Engineering Laboratory of Bridge and Tunnel Technology, Dalian University of Technology, Dalian, China. \\ ${ }^{2}$ College of Civil Engineering and Architecture, Dalian University, Dalian, China. \\ ${ }^{3}$ State Key Laboratory of Structural Analysis for Industrial Equipment, Dalian University of Technology, Dalian, China. \\ ${ }^{4}$ CSCEC Zhongyuan Architectural Design Institute Co.,Ltd., Zhengzhou, China.
}

\begin{abstract}
Vehicle or pedestrian loads can cause bridge vibration. The pedestrian load is essentially a stochastic process, and the vibration response of pedestrian bridges is also a stochastic process. In order to evaluate the human comfort of a pedestrian bridge comprehensively, this paper presents a comfort evaluation method based on stochastic process theory. The autocorrelation function of the displacement response of a pedestrian bridge under random pedestrian load is derived in this paper. On this basis, the root mean square (RMS) of acceleration is proposed as the comfort evaluation index. Taking an asymmetric single-tower cable-stayed bridge as an example, the modal analysis of the bridge is proceeded by finite element method (FEM). Then the acceleration time histories of four measuring points are obtained by field experiment. FEM results and field experiment results are used to analyse random vibration of the bridge. Through a field experiment and random vibration analysis of the bridge, the acceleration peak value evaluation index and the RMS of acceleration value evaluation index are compared. The results show that the RMS of acceleration index is more comprehensive and reasonable because it considers the whole-time history of the vibration response. The RMS of acceleration index is based on stochastic process theory, so it is more rigorous in mathematical expression and clearer in physical concept. It provides a reference for the evaluation of pedestrian bridge comfort.
\end{abstract}

Keywords: Acceleration mean square value, comfort, pedestrian bridge, random vibration.

\section{INTRODUCTION}

Vehicle or pedestrian loads can cause bridge vibration. If the vibration is high, it can influence the bridge comfort.
In the pursuit of bridge aesthetics, there is a trend in pedestrian bridge design to use a long and flexible structure, which creates the problem of pedestrianinduced vibration. London's Millennium Bridge, Singapore's Changi Mezzanine Bridge, Paris' Solferino Bridge, Japan's T Bridge, and other pedestrian bridges have the problem of excessive human vibration. Since the Millennium Bridge incident in London, scholars have conducted extensive research on the pedestrian-induced vibration of footbridges. Based on the experimental data of the Millennium Bridge in London, Dallard et al. (2001) analysed and proposed the interaction model of man-bridge and calculated the critical number of dynamic instability. Živanović et al. (2005) reviewed about 200 research studies that dealt with different aspects of the vibration serviceability of footbridges under human-induced load. It has been found that the whole issue is very complex and under-researched. Brownjohn et al. (2004) examined real continuous walking forces obtained from an instrumented treadmill and the effect of their random imperfections through a time simulation of the structural response. Chen and Liu (2009) compiled pedestrian footfall observation statistics. Piccardo and Tubino (2012) deduced a spectral model of the modal force induced by stationary groups of pedestrians, considering several sources of randomness. Krenk (2012) developed a frequency representation of vertical pedestrian load and a compact explicit formula for the magnitude of the resulting response. Caprani et al. (2012) predicted the vertical acceleration response of a hypothetical footbridge for a sample of

\footnotetext{
*Corresponding author (wanghuili@dlut.edu.cn; (10) https://orcid.org/0000-0002-0675-2524)
} 
Table 1: Limit value of footbridge comfort

\begin{tabular}{lcc}
\hline \multicolumn{1}{c}{ Standard } & Vertical & Transverse \\
\hline British BS 5400(9352, 2005) & $0.5 f^{0.5} \mathrm{~s}^{-0.5}$ & $0.25 \mathrm{~m} / \mathrm{s}^{2}$ \\
Germany EN03(RFS2-CT-2007-00033, 2008) & $1 \mathrm{~m} / \mathrm{s}^{2}$ & $0.3 \mathrm{~m} / \mathrm{s}^{2}$ \\
Canada OHBDC (Association, 1983) & $0.75 f^{0.75} \mathrm{~s}^{-0.75}$ & -- \\
ISO 3010(ISO, 2017) & $0.5-1.0 \mathrm{~m} / \mathrm{s}^{2}$ & $0.31 \mathrm{~m} / \mathrm{s}^{2} *$ \\
European EN 1990(CEN, 2002) & $0.7 \mathrm{~m} / \mathrm{s}^{2}$ & $\min \left(0.14 f^{0.5}, 0.15 \mathrm{~m} / \mathrm{s}^{2}\right)$ \\
\hline
\end{tabular}

$* f$ is natural frequency.

single pedestrians and a crowd of pedestrians using a probabilistic approach. Bassolia et al. (2018) evaluated the structural response to vertical pedestrian excitation for a wide range of footbridge and crowd parameters. The current comfort evaluation method mainly takes the acceleration peak as the evaluation index. It is thought that the largest vibration displacement point is the same as the peak acceleration point, so the present comfort evaluation method of a pedestrian bridge is based on the peak acceleration of the whole bridge (Heinemeyer et al., 2009). The limits of peak acceleration in different specifications are listed in Table 1.

However, the pedestrian load is essentially a narrow-band random process (Brownjohn et al., 2004). Therefore, the vibration response of a pedestrian bridge is a stochastic process. The exact values of acceleration and velocity cannot be obtained (Van Nimmen, 2014). The peak acceleration index cannot account for this process, so another evaluation index should be established. In this paper, stochastic process theory was used to analyse the pedestrian-induced vibration of a pedestrian bridge, and a method for evaluating the comfort level of a pedestrian bridge based on the stochastic process is proposed. It is more comprehensive and reasonable, because it considers the whole time-history of the vibration response.

\section{METHODOLOGY}

\section{Stochastic process theory for bridge}

The most important index to evaluate the vibration response of a pedestrian bridge is the comfort level. The pedestrian load is essentially a stochastic process, and the vibration response of pedestrian bridges is also a stochastic process. Therefore, the comfort level should be evaluated by the stochastic process method.
The pedestrian can only appear at a point in a certain time, so the acceleration means square at the maximal structure response point is representative. According to stochastic process theory, the mean square value is the value of the autocorrelation function if $\tau=t_{1}-t_{2}=0$, and it is also the maximum value of the autocorrelation function, that is

$\sigma_{X}^{2}=E\left\{X^{2}(t)\right\}=R_{X}(0)=\int_{-\infty}^{\infty} S_{X}(\omega) d \omega \geq\left|R_{X}(\tau)\right|$

where $R_{X}$ is the autocorrelation function. The value of $R_{X}(0)$ is equal to the total area under the power spectral density curve. $S_{X}$ is the power spectral density function. The mean square value is the average energy of the stationary stochastic process, which is equal to the average energy of each harmonic component.

The correlation function matrix of the acceleration response can be obtained by the stochastic vibration analysis of a pedestrian bridge. If the load is determined, the acceleration response of the structure is also determined. However, the walking speed of pedestrians has relation to the comfort of the bridge, and the pedestrians will pass through different positions of the bridge in a certain time. The variation of the pedestrian position corresponds to the different correlation function, and the different time course corresponds to a different value of $\tau$.

The dynamic formula of a bridge under pedestrian walking is

$$
M \ddot{u}(t)+C \dot{u}(t)+K u(t)=\sum_{i=1}^{N} X_{i}(t)
$$

where $M$ is mass matrix of bridge structure, $C$ is damp matrix of bridge structure, $K$ is stiffness matrix of 
bridge structure. $u(\mathrm{t})$ is the deformation vector, $\dot{u}(t)$ is the velocity vector, $\ddot{u}(t)$ is the acceleration vector. $X_{i}(\mathrm{t})$ is single person walking force vector. $\mathrm{N}$ is the number of persons. Suppose the stochastic model of the single person walking force is

$$
X_{i}(t)=A \sin (\omega t+\theta)+R
$$

where $A$ is the load amplitude, $\omega$ is the pedestrian step frequency, $\theta$ is the phase of the pedestrian load, which is a random variable uniformly distributed between $-\pi$ and $\pi$, and $\mathrm{R}$ is the static component of the pedestrian load.

According to stochastic vibration theory, the following equation is used:

$$
\sigma^{2}\left(\sum_{i=1}^{N} X_{i}\right)=\frac{1}{T} \int_{0}^{T}\left(\sum_{i=1}^{N} X_{i}\right)^{2} d t
$$

Equation (3) is substituted into Equation (4), then the following equation is used:

$$
\sigma^{2}\left(\sum_{i=1}^{N} X_{i}\right)=N \sigma^{2} X_{i}=N \frac{A^{2}}{2}
$$

If $\mathrm{N}$ pedestrians are uniformly distributed on a bridge with length ' $\mathrm{L}$ ', the $X(x, \mathrm{t})$ standard deviation distributed along the bridge is

$$
\sigma[X(x, t)]=\frac{\sqrt{N} A}{\sqrt{2} L}
$$

According to the central limit theorem, the sum of $\mathrm{N}$ pedestrian loads can be regarded as normal distribution, whose mean value is zero, and the standard deviation is given by the above formula. According to the guarantee rate of $95 \%$, the force acting evenly along the bridge $X(x, \mathrm{t})$ is

$$
X(x, t)=\frac{\sqrt{2 N} A}{L} \sin (\omega t+\theta)+N R
$$

The static component of the pedestrian load has no effect on the acceleration. According to stochastic vibration theory, the autocorrelation function of the pedestrian load is

$$
R_{X}(\tau)=\frac{A^{2}}{2} \cos \omega_{0} \tau
$$

The power spectral density function of the pedestrian loads can be obtained from the Wiener-Khintchine formula (Gadiyar \& Padma, 1999):

$$
\begin{aligned}
S_{X}(\omega) & =\int_{-\infty}^{\infty} \frac{A^{2}}{2} \cos \omega_{0} \tau \exp (-i \omega \tau) d \tau \\
& =\frac{A^{2}}{4}\left\{\int_{-\infty}^{\infty} \exp \left[i\left(\omega_{0}-\omega\right) \tau\right] d \tau+\int_{-\infty}^{\infty} \exp \left[-i\left(\omega_{0}+\omega\right) \tau\right] d \tau\right\} \\
& =\frac{A^{2}}{4}\left[\delta\left(\omega-\omega_{0}\right)+\delta\left(\omega+\omega_{0}\right)\right]
\end{aligned}
$$

The input power spectrum density is a narrow band random process at the main frequency.

\section{A pedestrian cable-stayed bridge}

The pedestrian bridge selected is an asymmetric singletower cable-stayed bridge, as shown in Figure 1. The span of the bridge is $58.7+21.3=80 \mathrm{~m}$, and the width is $6 \mathrm{~m}$. The tower is a reinforced concrete arch structure with a solid rectangular cross section. The slope of the tower is 10 degrees to the side span. The tower is $28.2 \mathrm{~m}$ high, and the height above the deck is $24.1 \mathrm{~m}$. The girder is a steel tube truss structure. The upper chord and lower chord are set in the shape of a 'W', as shown in Figure 2.

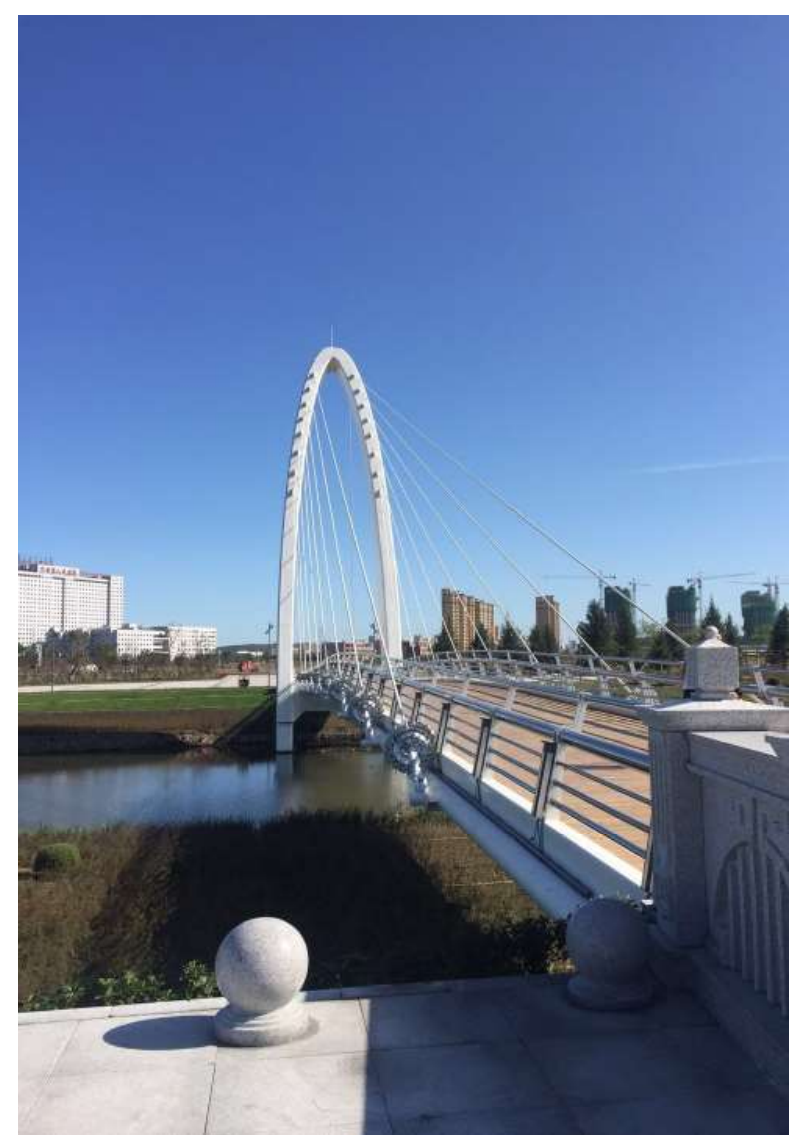

Figure 1: Picture of the pedestrian bridge 


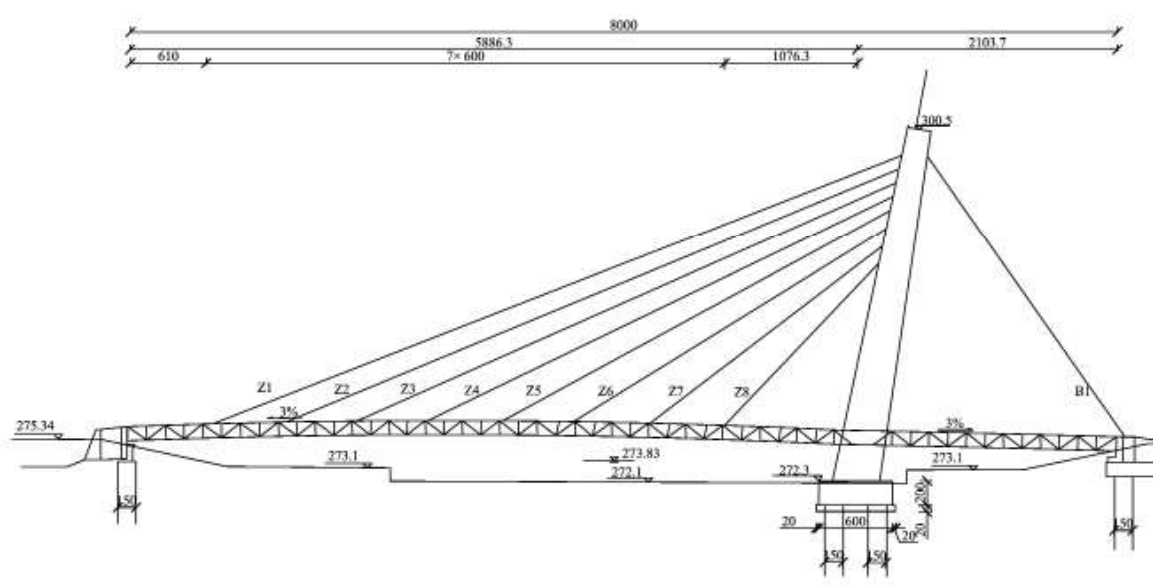

a. elevalıul rayuu

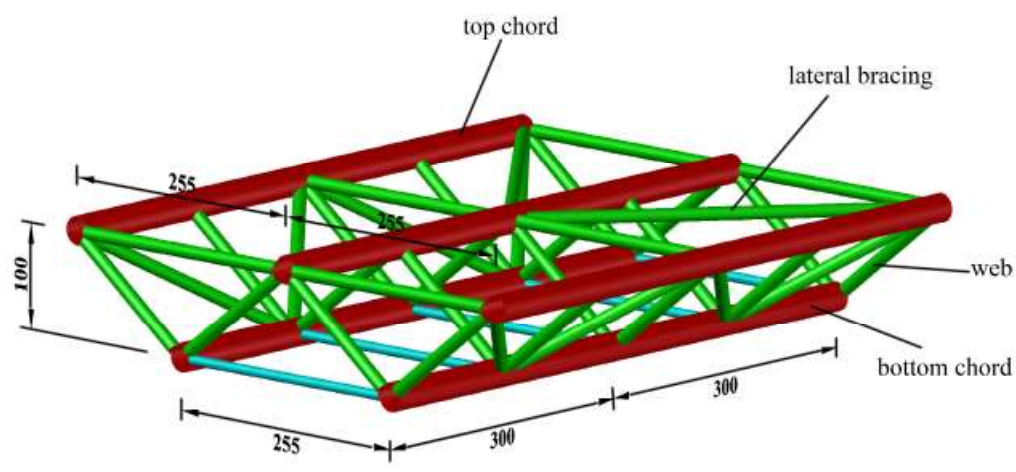

b. truss

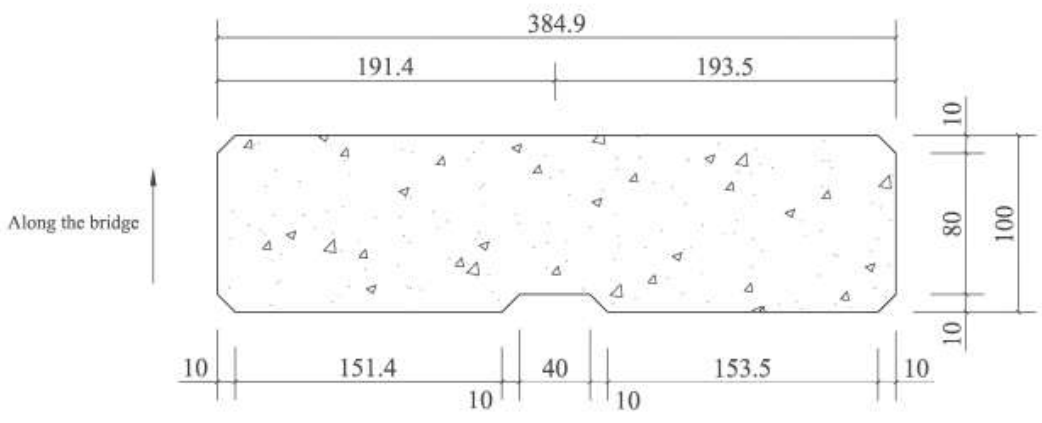

A-A section

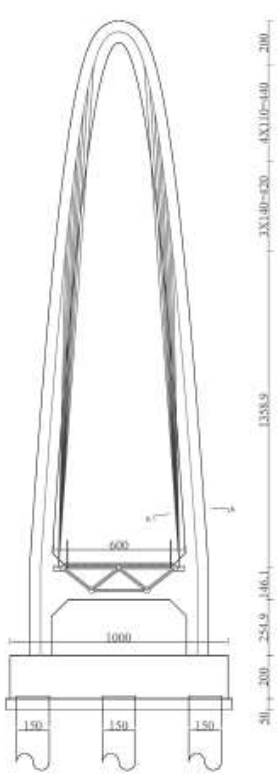

c. tower

Figure 2: General layout of bridge $/ \mathrm{cm}$ 


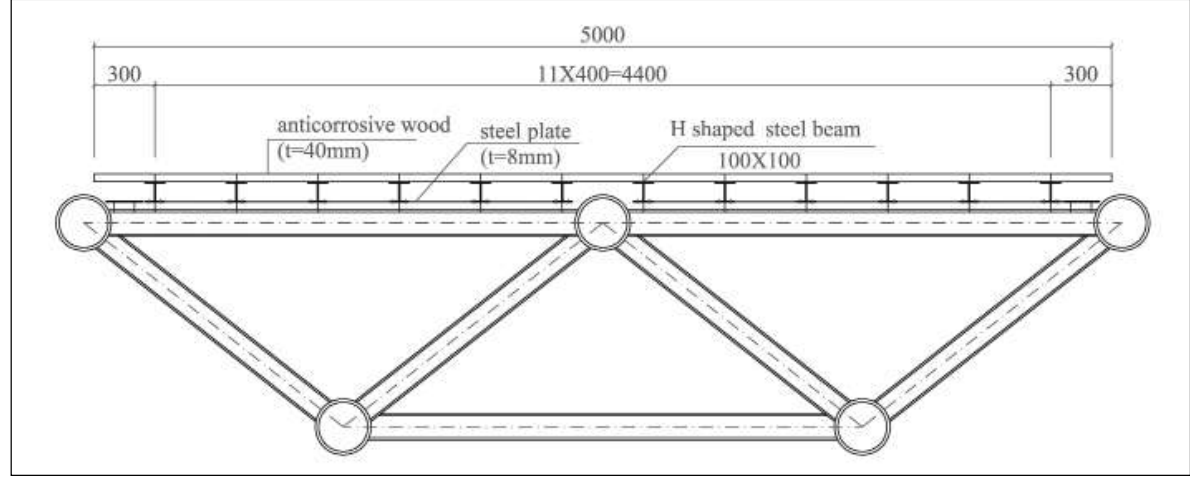

Figure 3: Deck of bridge $/ \mathrm{mm}$

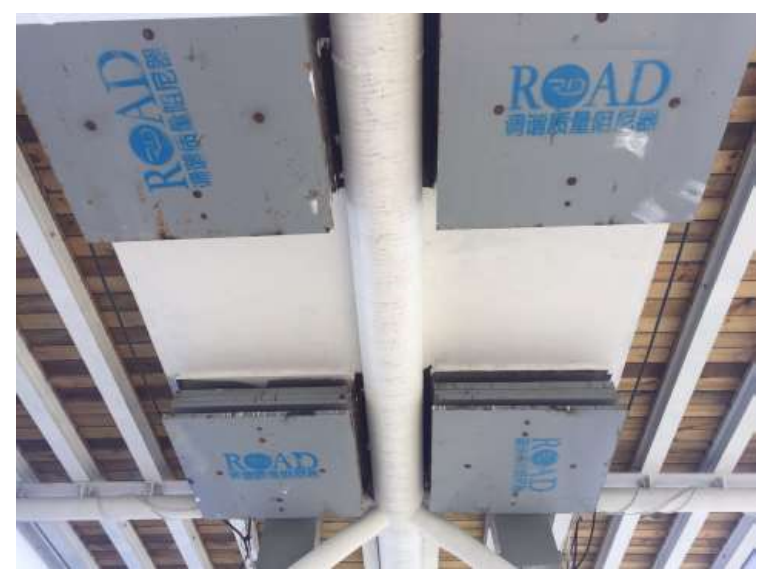

Figure 4: TMD under the girder
The chords are made of $\Phi 273 \times 16 \mathrm{~mm}$ steel tube filled with C40 concrete. The webs are made of $\Phi 127 \times 10$ $\mathrm{mm}$ steel tube and the lateral bracing are made of $\Phi 95$ $\times 7 \mathrm{~mm}$ steel tubes. All members are welded. The deck is put on the girder, which is composed of $\mathrm{H}$ shape steel beam, steel plate and anticorrosive wood, as shown in Figure 3.There are 8 pairs of spatial cables, which are made of $73 \Phi 7 \mathrm{~mm}$ high-strength galvanised steel wires with a polyethylene cover. The ultimate tensile strength of the hanger is $1670 \mathrm{MPa}$. The cable space at the girder is $6 \mathrm{~m}$ and at the tower is between $1.1 \mathrm{~m}$ and $1.4 \mathrm{~m}$. Both the girder and tower are fixed. The girder is supported at both abutments. Four tuned mass dampers (TMD) are installed at the middle span, as shown in Figure 4. The weight of one TMD is $5 \mathrm{KN}$. The damp of the TMD is 0.05 . The natural frequency of the TMD is $1.6 \mathrm{~Hz}$.

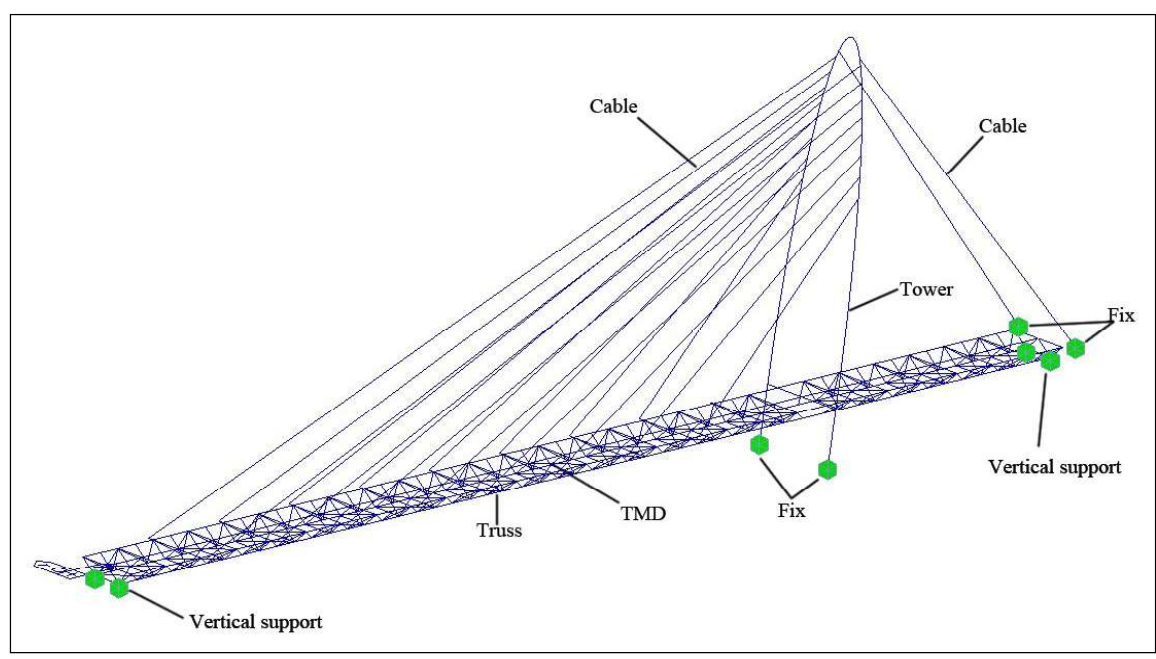

Figure 5: Bridge FEM model diagram 


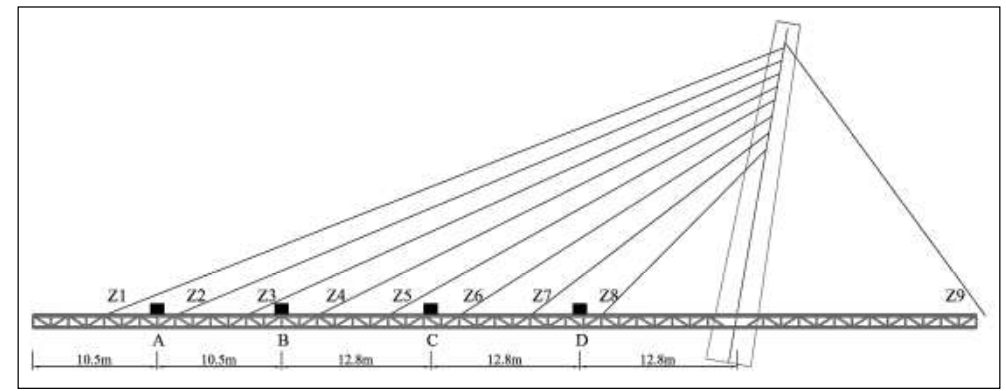

Figure 6: Acceleration sensors layout

\section{The finite element method model}

The tower and girder are simulated with 3D beam element. The cable is simulated with link element. However, cable is flexible while link element is straight. The cable sag is depended on tension, so the equivalent module is used for link element, as shown in equation (10). This is Ernst effect.

$$
E_{e q}=\frac{E}{1+\frac{q^{2} L^{2} A}{12 T^{3}} E}
$$

Where $E_{e q}$ is equivalent module of cables, $E$ is module of cables, $q$ is weight of cable per length, $A$ is area of cable and $T$ is tension of cable.

The TMD is simulated with mass element and spring element. The FEM model diagram is shown in Figure 5, and there are 1208 elements.

\section{Modal analysis}

Stochastic vibration analysis begins with power spectral density (PSD). Then independent vibration equations should be obtained with the modal analysis method.

\section{Field experiment}

Four acceleration sensors A, B, C and D were set up on the top of the deck. They are along the centre line of bridge deck, as shown in Figure 6 . The sensitivity of acceleration sensors is $0.3 \mathrm{~V} / \mathrm{m} / \mathrm{s}^{2}$. The measuring range of acceleration sensors is $20 \mathrm{~m} / \mathrm{s}^{2}$. The pass-band of acceleration sensors is $0.25-80 \mathrm{~Hz}$.

\section{RESULTS AND DISCUSSION}

\section{Results}

\section{Modal analysis results}

The natural frequencies of the bridge were obtained with FEM and are listed in Table 2. The first 20 order modes were found. Only the modes in relation to girder vertical bending are listed, because the vertical motion of the girder was the focus of the study.

Table 2: Natural frequency

\begin{tabular}{cccccccc}
\hline $\begin{array}{c}\text { Mode order } \\
\text { Frequency }\end{array}$ & 1 & 5 & 6 & 11 & 12 & 16 & 20 \\
$(\mathrm{~Hz})$ & 1.75 & 3.65 & 3.99 & 6.18 & 7.38 & 8.90 & 12.05 \\
\hline
\end{tabular}

The higher order frequencies influence only a little of the vibration of the bridge. Therefore, only the first, fifth, and sixth orders were selected, and their mode shapes can be seen in Figure 7. The first natural frequency is $1.75 \mathrm{~Hz}$, and so the first mode shape is the first-order girder vertical bending. The fifth $(3.65 \mathrm{~Hz})$ and sixth $(3.99 \mathrm{~Hz})$ natural frequencies are given as the second- and thirdorder girder vertical bendings, respectively.

\section{Field experiment results}

The experiment adopted the artificial excitation method to stimulate the bridge at Point $\mathrm{B}$, and the experimental 
load cases are listed in Table 3. In general, excitation methods for bridge dynamic performance test include ambient vibration and external load excitation. The single person jumping at mid-span and a foot formation with 9 persons from bridge head to bridge end were external load excitations. The average weight of each person is $0.7 \mathrm{kN}$. These external load excitations could excite kinds of structure modes. The structure's natural frequency is $1.75 \mathrm{~Hz}$ and the human stride frequency is about $2.0 \mathrm{~Hz}$ (Leonard, 1996). Therefore, the excitation frequencies are $1.7 \mathrm{~Hz}$ and $2.0 \mathrm{~Hz}$.

The acceleration time histories of four measuring points were picked up with acceleration sensors. Based on the Nyquist-Shannon sampling theorem (RomoCárdenas et al., 2018), the sampling frequency was set as $102.4 \mathrm{~Hz}$ and the analytical frequency was set as 51.2 $\mathrm{Hz}$. There were a lot of results; only the measurements of Sensor A in Load Case 2 and Load Case 6 are shown in Figures 8, 9.

Figure 8 shows that the acceleration response cantered at $1.7 \mathrm{~Hz}$ without the TMD; this was because the load frequency was close to the first-order natural frequency. Figure 9 shows that the acceleration response cantered at $3.5 \mathrm{~Hz}$ with the TMD; this was because the load frequency was close to the fifth-order natural frequency. This indicates that the structural characteristics changed with the TMD.

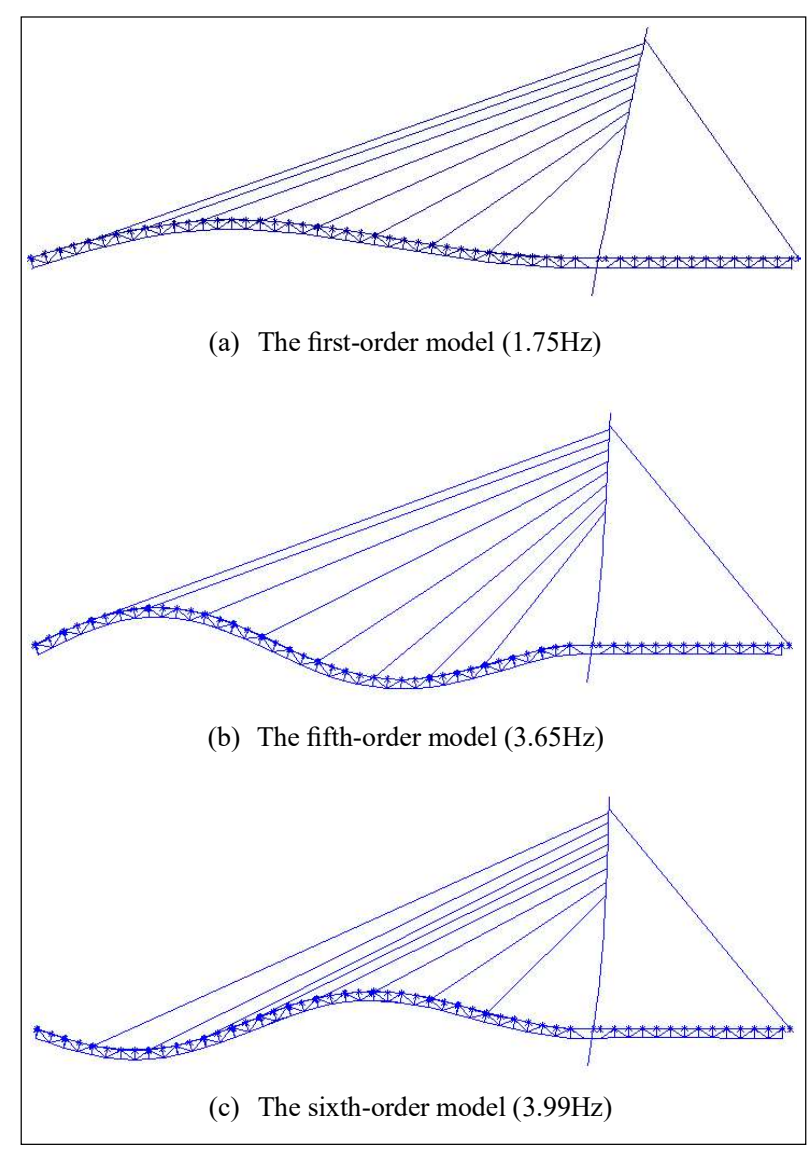

Figure 7: Vibration model of the pedestrian bridge

Table 3: Summary statement of load cases

\begin{tabular}{lllc}
\hline Load case & Experimental purpose & Excitation mode & Excitation frequency $(\mathrm{Hz})$ \\
\hline 1 & Measured natural vibration frequency & Ambient vibration & -- \\
2 & Acceleration time history without TMD & A foot formation with 9 persons & 1.7 \\
3 & Acceleration time history without TMD & A foot formation with 9 persons & 2.0 \\
4 & Acceleration time history without TMD & Single person jumping at mid-span & 1.7 \\
5 & Acceleration time history without TMD & Single person jumping at mid-span & 2.0 \\
6 & Acceleration time history with TMD & A foot formation with 9 persons & 1.7 \\
7 & Acceleration time history with TMD & A foot formation with 9 persons & 2.0 \\
8 & Acceleration time history with TMD & Single person jumping at mid-span & 1.7 \\
9 & Acceleration time history with TMD & Single person jumping at mid-span & 2.0 \\
\hline
\end{tabular}




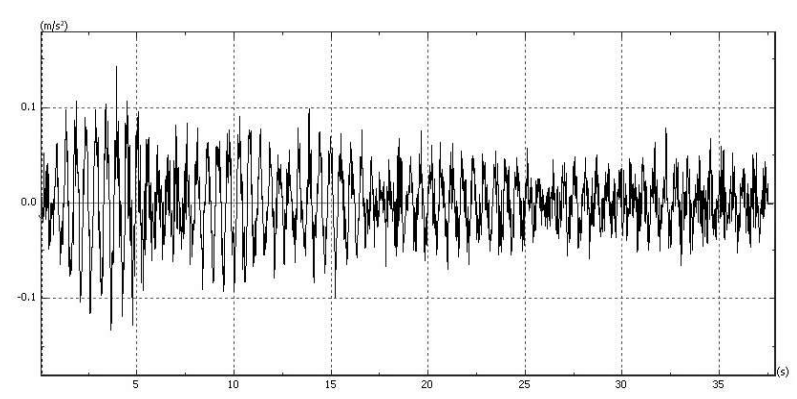

(a) Acceleration time-history curve of sensor A

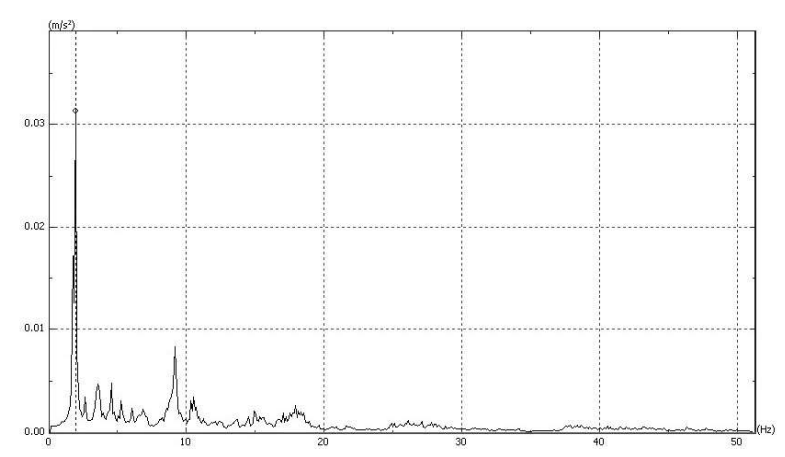

(b) Acceleration spectrum curve of sensor A

Figure 8: Results of load case 2

\section{Discussion}

\section{RMS of acceleration analysis}

In stochastic vibration analysis, displacement, velocity, and acceleration time-history are the only values in the sense of probability. Assuming that the acceleration is subject to normal distribution $N(0, \sigma)$ with a zero mean, the probability density can be calculated inversely according to the correlation function.

The RMS of acceleration summary compared with field measured data is listed in Table 4.

Table 4 shows that the data of the random vibration analysis and the field experiment at Points A, B, and C was similar. This indicates that the random vibration method is a feasible method to analyse the pedestrianinduced vibration of a pedestrian bridge. However, there were errors at Point D. This result is because pedestrian walking is a narrow-band random process, so the vibration

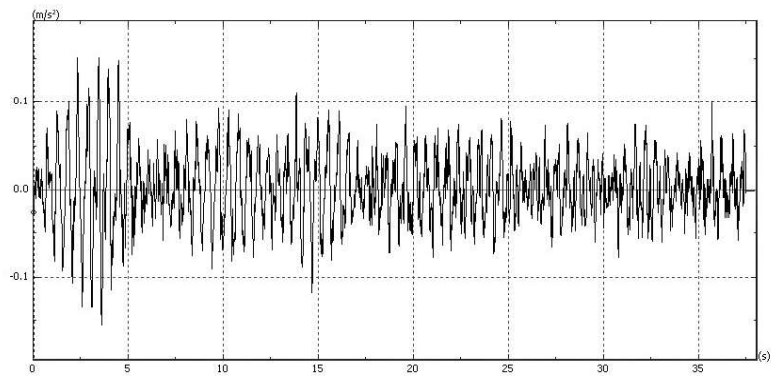

(a) Acceleration time-history curve of sensor A

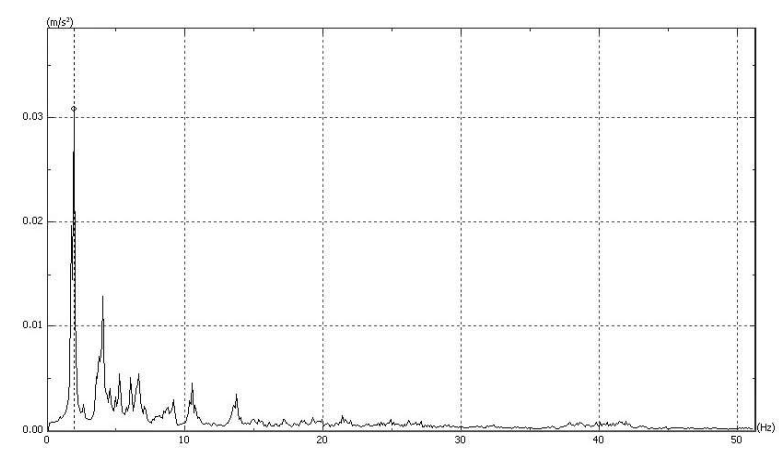

(b) Acceleration spectrum curve of sensor A

Figure 9: Results of load case 6

was based mainly on the first-order vibration mode. The response of Point $\mathrm{D}$ in the first-order vibration mode was small. In the field experiment, the pedestrian load was not a harmonic load and there were components of other frequencies. Therefore, the excited vibration contained multiple frequencies. This caused errors at Point D.

\section{Vibration reduction rate analysis}

The dimension of the RMS of acceleration is the same as acceleration. Hence, RMS of acceleration was compared with peak acceleration and the values are listed in Table 5.

It can be seen from Table 5 that the vibration of the pedestrian bridge was relatively large without the TMD. However, the vibration of the pedestrian bridge was reduced with the TMD. The minimum and maximum peak acceleration vibration reduction rates were $15.69 \%$ and $41.78 \%$, respectively. The average peak acceleration vibration reduction rates was $28.39 \%$. 
Table 4: RMS of acceleration of measured and analysis

\begin{tabular}{|c|c|c|c|c|c|}
\hline \multirow[b]{2}{*}{ Load case } & \multirow{2}{*}{$\begin{array}{l}\text { Measuring point } \\
\text { number }\end{array}$} & \multicolumn{2}{|c|}{ Without TMD } & \multicolumn{2}{|c|}{ With TMD } \\
\hline & & Measured & $\begin{array}{c}\text { Random vibration } \\
\text { analysis }\end{array}$ & Measured & $\begin{array}{c}\text { Random vibration } \\
\text { analysis }\end{array}$ \\
\hline \multirow{4}{*}{$\begin{array}{l}\text { Formation } \\
\text { with } 9 \text { persons } \\
1.7 \mathrm{~Hz}\end{array}$} & A & 0.025 & 0.034 & 0.022 & 0.028 \\
\hline & B & 0.039 & 0.040 & 0.034 & 0.035 \\
\hline & $\mathrm{C}$ & 0.028 & 0.033 & 0.034 & 0.039 \\
\hline & $\mathrm{D}$ & 0.036 & 0.008 & 0.035 & 0.009 \\
\hline \multirow{4}{*}{$\begin{array}{l}\text { Formation } \\
\text { with } 9 \text { persons } \\
2.0 \mathrm{~Hz}\end{array}$} & A & 0.045 & 0.060 & 0.029 & 0.039 \\
\hline & B & 0.081 & 0.083 & 0.052 & 0.053 \\
\hline & $\mathrm{C}$ & 0.058 & 0.068 & 0.038 & 0.045 \\
\hline & $\mathrm{D}$ & 0.071 & 0.022 & 0.046 & 0.012 \\
\hline \multirow{4}{*}{$\begin{array}{l}\text { Single person } \\
\text { jumping } 1.7 \mathrm{~Hz}\end{array}$} & A & 0.033 & 0.042 & 0.023 & 0.031 \\
\hline & B & 0.052 & 0.053 & 0.037 & 0.038 \\
\hline & $\mathrm{C}$ & 0.035 & 0.041 & 0.026 & 0.030 \\
\hline & $\mathrm{D}$ & 0.047 & 0.012 & 0.034 & 0.010 \\
\hline \multirow{4}{*}{$\begin{array}{l}\text { Single person } \\
\text { jumping } 2.0 \mathrm{~Hz}\end{array}$} & A & 0.125 & 0.162 & 0.097 & 0.126 \\
\hline & B & 0.216 & 0.222 & 0.167 & 0.172 \\
\hline & $\mathrm{C}$ & 0.147 & 0.170 & 0.116 & 0.135 \\
\hline & $\mathrm{D}$ & 0.193 & 0.050 & 0.135 & 0.042 \\
\hline
\end{tabular}

Table 5: RMS of acceleration and peak acceleration values $\left(\mathrm{m} / \mathrm{s}^{2}\right)$

\begin{tabular}{|c|c|c|c|c|c|c|c|}
\hline \multirow[b]{2}{*}{ Load case } & \multirow{2}{*}{$\begin{array}{c}\text { Measuring } \\
\text { point } \\
\text { number }\end{array}$} & \multicolumn{3}{|c|}{ Peak acceleration } & \multicolumn{3}{|c|}{ RMS of acceleration } \\
\hline & & Without TMD & With TMD & $\begin{array}{l}\text { Vibration reduc- } \\
\text { tion rate }\end{array}$ & Without TMD & With TMD & $\begin{array}{c}\text { Vibration reduc- } \\
\text { tion rate }\end{array}$ \\
\hline \multirow{4}{*}{$\begin{array}{l}\text { Formation with } 9 \\
\text { persons } 1.7 \mathrm{~Hz}\end{array}$} & A & 0.1429 & 0.0866 & $39.40 \%$ & 0.0254 & 0.022 & $13.39 \%$ \\
\hline & B & 0.230 & 0.1339 & $41.78 \%$ & 0.0393 & 0.0336 & $14.50 \%$ \\
\hline & $\mathrm{C}$ & 0.1547 & 0.1127 & $27.15 \%$ & 0.0282 & 0.034 & $-20.57 \%$ \\
\hline & $\mathrm{D}$ & 0.1728 & 0.1194 & $30.90 \%$ & 0.0355 & 0.0351 & $1.13 \%$ \\
\hline \multirow{4}{*}{$\begin{array}{l}\text { Formation with } 9 \\
\text { persons } 2.0 \mathrm{~Hz}\end{array}$} & A & 0.1656 & 0.1213 & $26.75 \%$ & 0.0452 & 0.0292 & $35.40 \%$ \\
\hline & B & 0.2711 & 0.1881 & $30.62 \%$ & 0.0807 & 0.0518 & $35.81 \%$ \\
\hline & $\mathrm{C}$ & 0.236 & 0.1645 & $30.30 \%$ & 0.0581 & 0.0383 & $34.08 \%$ \\
\hline & $\mathrm{D}$ & 0.2234 & 0.1639 & $26.63 \%$ & 0.0711 & 0.0459 & $35.44 \%$ \\
\hline \multirow{4}{*}{$\begin{array}{l}\text { Single person } \\
\text { jumping } 1.7 \mathrm{~Hz}\end{array}$} & A & 0.1666 & 0.1126 & $32.41 \%$ & 0.0328 & 0.0233 & $28.96 \%$ \\
\hline & B & 0.2027 & 0.1709 & $15.69 \%$ & 0.0517 & 0.0366 & $29.21 \%$ \\
\hline & $\mathrm{C}$ & 0.1557 & 0.115 & $26.14 \%$ & 0.0354 & 0.0261 & $26.27 \%$ \\
\hline & $\mathrm{D}$ & 0.2087 & 0.1607 & $23.00 \%$ & 0.0473 & 0.034 & $28.12 \%$ \\
\hline \multirow{4}{*}{$\begin{array}{l}\text { Single person } \\
\text { jumping } 2.0 \mathrm{~Hz}\end{array}$} & A & 0.2691 & 0.2014 & $25.16 \%$ & 0.125 & 0.0973 & $22.16 \%$ \\
\hline & B & 0.4115 & 0.3177 & $22.79 \%$ & 0.2155 & 0.1673 & $22.37 \%$ \\
\hline & $\mathrm{C}$ & 0.3247 & 0.2347 & $27.72 \%$ & 0.1471 & 0.1158 & $21.28 \%$ \\
\hline & $\mathrm{D}$ & 0.3608 & 0.2605 & $27.80 \%$ & 0.1932 & 0.1345 & $30.38 \%$ \\
\hline
\end{tabular}


The average RMS of acceleration vibration reduction rate was $22.37 \%$, which is close to the result of the peak acceleration. However, the RMS of acceleration vibration reduction rate at Point $\mathrm{C}$ was negative in Load Case 2, which means that the RMS of acceleration response became larger with the TMD. The reasons for the negative vibration efficiency with the TMD are as follows:

(1) A TMD can change the dynamic characteristics of the original structure. Figure9 (b) shows that the secondorder frequency changed into a sensitive frequency with the TMD. Therefore, the RMS of acceleration became larger with the TMD.

(2) The external incentive had a deviation and was not an accurate $1.7 \mathrm{~Hz}$ harmonic load.

There is a certain difference between the peak acceleration evaluation results and the RMS of acceleration evaluation results. According to the theory of random vibration, the response of a linear system under a stationary random load will change from a nonstationary process to a stationary process and the mean square value of the transition will gradually increase. The acceleration mean square value is max in a stationary stage, while the instantaneous acceleration value may reach the maximum in a non-stationary stage. Figure 8(b) shows that the acceleration maximum happened in a non-stationary stage before TMD installation. Therefore, it is more reasonable to use the RMS of acceleration as the evaluation index.

\section{CONCLUSIONS}

Based on stochastic process theory, the autocorrelation function of the displacement response of a pedestrian bridge under a random pedestrian load is derived in this paper. On this basis, an evaluation method using the mean square value of acceleration at the maximum vibration response of a pedestrian bridge is proposed as the comfort evaluation index. The conclusions of this research are as follows:

(1) The pedestrian-induced vibration response of a pedestrian bridge is a stochastic process. However, the peak acceleration evaluation index ignores the vibration process. Therefore, it is more reasonable to evaluate pedestrian bridges based on stochastic process theory;

(2) With random vibration analysis and a field experiment of a cable-stayed pedestrian bridge, this research has shown that the RMS of acceleration index based on stochastic process theory is more rigorous in mathematical expression and clearer in physical concept than any other index. It provides a reference for the evaluation of pedestrian bridge comfort.

\section{Acknowledgement}

This work was supported by the Foundation of Liaoning Provincial Nature Fund Guidance Projects (2019-ZD0006,2019-ZD-0145), the Foundation of Liaoning Provincial Doctoral Scientific Research Projects (20170520138), the Foundation of Liaoning Provincial Department of Education Projects (L2014027).

\section{REFERENCES}

BS5400-10. Steel Concrete and Composite Bridges (2005). British Standards Association, London, UK.

Association C.S. (1983). Ontario Highway Bridge Design Code, Highway Engineering Division (OHBDC), Ministry of Transportation and Communication, Ontario, Canada.

Bassolia E., Van Nimmen K., Vincenzia L. \& Van den Broeck P. (2018). A spectral load model for pedestrian excitation including vertical humanstructure interaction. Engineering Structures 156: 537-547.

DOI: https://doi.org/10.1016/j.engstruct.2017.11.050

Brownjohn J.M.W., Pavic A. \& Omenzetter P. (2004). A spectral density approach for modelling continuous vertical forces on pedestrian structures due to walking. Canadian Journal of Civil Engineering 31: 65-77.

DOI: https://doi.org/10.1139/103-072

Caprani C.C., Keogh J., Archbold P. \& Fanning P. (2012). Enhancement factors for the vertical response of footbridges subjected to stochastic crowd loading. Computers and Structures 102-103: 87-96. DOI: https://doi.org/10.1016/j.compstruc.2012.03.006

CEN (2002). EN (1990). Eurocode 0: Basis of Structural Design. The European Committee for Standardization (CEN) and the European Committee for Electrotechnical Standardization (CENELEC), Brussels, Belgium.

Chen Z.Q. \& Liu G.D. (2009). Pedestrian-induced vibration theory and dynamic design of footbridges. Engineering Mechanics 12: 148-159.

Dallard P., Fitzpatrick T., Flint A.J.A. \& Le Bourva S. (2001). The London millennuim footbridge. The Structural Engineer 79: 17-33.

Gadiyar H.G. \& Padma R. (1999). Ramanujan-Fourier series, the Wiener-Khintchine formula and the distribution of prime pairs. Physica A: Statistical Mechanics and its Applications 269: 503-510. DOI: https://doi.org/10.1016/S0378-4371(99)00171-5

Heinemeyer C. et al. (12 authors) (2009). Design of Lightweight Footbridges for Human Induced Vibrations. European Commission, Luxembourg. 
ISO 2017. ISO 3010, Bases for Design of Structures. International Standardization Organization Geneva, Switzerland.

Van Nimmen K., Lombaert G., De Roeck G. \& Van den Broeck P. (2014). Vibration serviceability of footbridges: evaluation of the current codes of practice. Engineering Structures 59: 448-461.

DOI: https://doi.org/10.1016/j.engstruct.2013.11.006

Krenk S. (2012). Dynamic response to pedestrian loads with statistical frequency distribution. Journal of Engineering Mechanics 138: 1275-1281.

DOI: https://doi.org/10.1061/(ASCE)EM.1943-7889.0000425

Leonard D.R. (1996). Human Tolerance Levels for Bridge Vibrations. RRL Report No. 34. Ministry of Transport Road Research Laboratory. Harmondsworth, England.

Piccardo G. \& Tubino F. (2012). Equivalent spectral model and maximum dynamic response for the serviceability analysis of footbridges. Engineering Structures 40: 445-456.

DOI: https://doi.org/10.1016/j.engstruct.2012.03.005

RFS2-CT-2007-00033 2008. Design of Footbridges Guideline EN03.

Romo-Cárdenas G., Avilés-Rodríguez G.J., de D.SánchezLópez J., Cosío-Leónb M., Luque P.A., Gómez-Gutiérrez C.M., Nieto-Hipólito J.I., Vázquez-Brise M. \& NavarroCota C.X. (2018). Nyquist-Shannon theorem application for Savitzky-Golay smoothing window size parameter determination in bio-optical signals. Results in Physics 11: 17-22.

DOI: https://doi.org/10.1016/j.rinp.2018.08.033

Živanović S., Pavic A. \& Reynolds P. (2005). Vibration serviceability of footbridges under human-induced excitation: a literature review. Journal of Sound and Vibration 279: 1-74.

DOI: https://doi.org/10.1016/j.jsv.2004.01.019 